05

\title{
Взаимодействие ферромагнитных слоев через магнитную перемычку
}

\author{
() И.Ю. Пашенькин, Р.В. Горев, А.А. Фраерман
}

Институт фризики микроструктур РАН,

Нижний Новгород, Россия

E-mail: pashenkin@ipmras.ru

Поступила в Редакцию 15 апреля 2019 г.

В окончательной редакции 22 апреля 2019 г.

Принята к публикации 24 апреля 2019 г.

Методами микромагнитного моделирования исследована зависимость структуры и энергии доменной стенки, локализованной в области магнитной перемычки между ферромагнитными пленками, от геометрических параметров системы. Продемонстрирован эффект смещения и изменения формы кривой намагничивания магнитомягкого слоя, вызванный обменным взаимодействием с магнитожестким слоем через магнитный филамент.

Ключевые слова: обменное взаимодействие, магнитный филамент, доменная стенка, микромагнитное моделирование.

DOI: $10.21883 /$ FTT.2019.09.48105.10N

\section{1. Введение}

Поиск способов управления магнитными состояниями в магнитных наносистемах электрическим полем является одной из наиболее актуальных задач магнетизма. В частности, возможность изменения взаимной ориентации намагниченности ферромагнитных слоев в спиновом клапане приложением электрического напряжения открывает широкие перспективы для создания элементов энергонезависимой магнитной памяти. Управление намагниченностью свободного (магнитомягкого) ферромагнитного слоя может быть осуществлено посредством организации обменного взаимодействия с закрепленным (магнитожестким) слоем. Одним из возможных путей является использование механизма резистивного переключения мемристорных структур металл-диэлектрик-металл $(M / D / M)$ с образованием металлических филаментов. Так, в работе [1] продемонстрирована возможность спинового транспорта через медный филамент в структурах $\mathrm{Co} / \mathrm{TaO}_{x} / \mathrm{Cu} / \mathrm{Py}$. Авторы наблюдали эффект магнетосопротивления, возникающий после резистивного переключения. Однако слабого РККИ взаимодействия недостаточно для наблюдения в экспериментах заметного эффекта подмагничивания свободного слоя, учитывая малые размеры филаментов $(10-30 \mathrm{~nm})$, получаемых в экспериментах с мемристорными структурами [2-3]. Более предпочтительной для решения задачи управления была бы организация прямого обмена между ферромагнитными берегами через магнитную перемычку. В работе [4] показана возможность контролируемого образования филаментов Со в структурах $\mathrm{Co} / \mathrm{ZnO} / \mathrm{Fe}$, что выражается в наблюдении эффекта туннельного магнетосопротивления, возникающего после приложения к ним напряжения величиной около $5 \mathrm{~V}$, сопровождающегося падением сопротивления с $10 \mathrm{M} \Omega$ до нескольких сотен $\mathrm{k} \Omega$.
В настоящей работе методом микромагнитного моделирования исследовалась зависимость структуры и энергии доменной стенки, локализованной в области перемычки между магнитными берегами от геометрических параметров системы. Также продемонстрирован эффект смещения кривой намагничивания свободного ферромагнитного слоя за счет образования „обменной пружины“ [5], связывающей его с закрепленным слоем.

\section{2. Методика расчета}

Исследованная система представляла собой набор ферромагнитных цилиндрических перемычек, разделяющих тонкие пленки из того же материала (рис. 1). Толщина пленок $h_{1}=10 \mathrm{~nm}$, диаметр цилиндров $d_{0}=20 \mathrm{~nm}$. Высота перемычек $h$ варьировалась от 16 до $0.6 \mathrm{~nm}$. Моделирование проводилось на основе численного решения уравнения Ландау-Лифшица для намагниченности образца с использованием пакета OOMMF [6], при этом использовались периодические

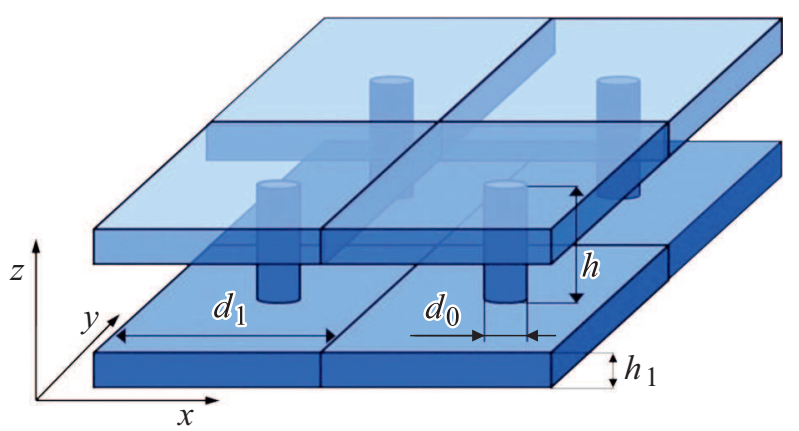

Рис. 1. Схематическое изображение исследуемой системы. $d_{0}$ - диаметр перемычки, $h-$ высота перемычки, $d_{1}-$ период перемычек, $h_{1}$ - толщина пленок. 
граничные условия (период $d_{1}=100 \mathrm{~nm}$ ). Материальные параметры системы соответствуют пленкам Co: постоянная обменного взаимодействия $A=3 \cdot 10^{-11} \mathrm{~J} / \mathrm{m}$, намагниченность насыщения $M_{s}=1.4 \cdot 10^{6} \mathrm{~A} / \mathrm{m}$. В модели предполагалось, что ось легкого намагничивания лежит в плоскости пленок и направлена вдоль оси $x$, константа одноосной анизотропии $K=5.4 \cdot 10^{5} \mathrm{~J} / \mathrm{m}^{3}$. Размер ячейки численной сетки составлял $1 \times 1 \times 1 \mathrm{~nm}$ при $h \geq 5 \mathrm{~nm}, 1 \times 1 \times 0.5 \mathrm{~nm}$ при $2 \leq h \leq 4$ и $1 \times 1 \times 0.2 \mathrm{~nm}$ при $h \leq 1 \mathrm{~nm}$. В качестве начальных условий была выбрана конфигурация, при которой ферромагнитные берега намагничены до насыщения противоположно друг другу вдоль оси легкого намагничивания. Далее распределение намагниченности релаксировало к равновесному с формированием доменной стенки, после чего вычислялась полная энергия системы.

\section{3. Результаты и обсуждение}

Аналогичная задача была теоретически рассмотрена в работе [7], где исследовалась зависимость формы и энергии доменной стенки, локализованной в области сужения, разделяющего ферромагнитные берега, от геометрических параметров системы, таких как отношение ширины доменной стенки в отсутствие сужения к длине перемычки $w_{0} / h$, отношение площадей поперечного сечения узкой области и берегов $S_{1} / S_{0}$. Ширина доменной стенки определяется соотношением обменной энергии и энергии анизотропии

$$
w_{0}=4 \sqrt{A / K}
$$

Для случая $w_{0} / h \leq 1$, энергия доменной стенки записывается как [7]:

$$
E_{d w}=\gamma S_{0},
$$

где $\gamma=4 \sqrt{A K}, S_{0}$ - площадь сечения перемычки.

В случае $1 \leq w_{0} / h \leq S_{1} / S_{0}$, где $S_{1}-$ площадь сечения берегов, энергия доменной стенки определяется геометрией системы [7]:

$$
E_{d w}=\pi^{2} A S_{0} / h .
$$

Для выбранных материальных параметров модели величина $w_{0}$ составила $9.6 \mathrm{~nm}$. На рис. 2 представлена зависимость энергии доменной стенки от соотношения $w_{0} / h$, полученная при микромагнитном моделировании (кривая 1) и аналитически в [7] (кривая 2).

Численные расчеты показывают, что при $h \geq w_{0}$ энергия доменной стенки перестает зависеть от $h$, что соответствует теоретической модели [7]. Такой результат объясняется тем, что стенка целиком лежит внутри перемычки и не „чувствует“ берегов. При $h \leq w_{0}$ энергия стенки $E_{d w} \propto 1 / h$. Значительно более резкое возрастание аналитической зависимости $E_{d w}(1 / h)$ связано с тем допущением, что магнитный момент М зависит только от координаты $z$, перпендикулярной плоскости пленок, то есть, намагниченность послойно однородна. Таким образом, при уменьшении длины перемычки доменная стенка „зажимается“ между берегами, что увеличивает плотность ее энергии. Выход доменной стенки в слои означал бы резкое увеличение ее объема за счет большо-

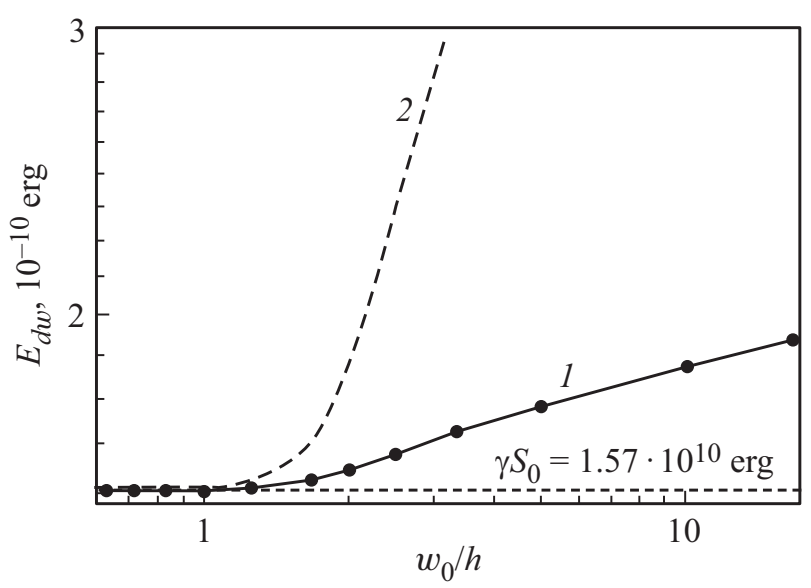

Рис. 2. Зависимость энергии доменной стенки от соотношения $w_{0} / h$, полученная при микромагнитном моделировании (кривая 1) и аналитически [7] (кривая 2).

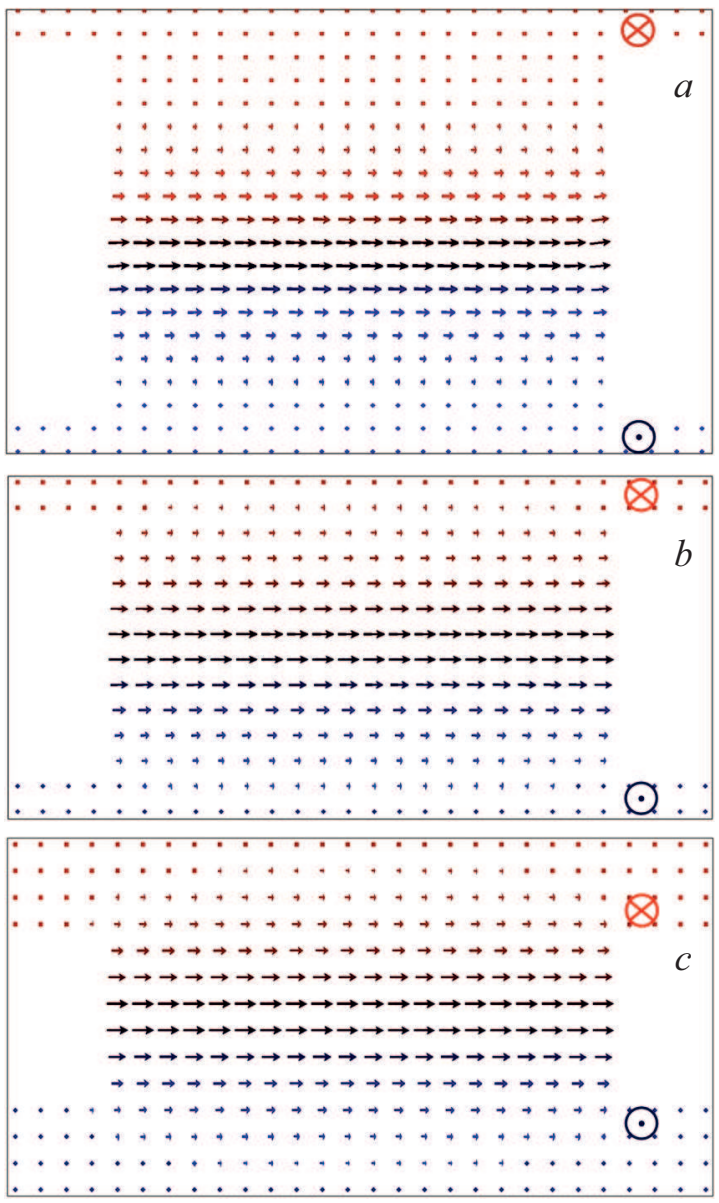

Рис. 3. Численно рассчитанное распределение намагниченности в доменной стенке в равновесном состоянии. $a) h=16 \mathrm{~nm}$, b) $h=10 \mathrm{~nm}, c) h=6 \mathrm{~nm}$. Видно, что при уменьшении длины перемычки доменная стенка заходит в слои. 


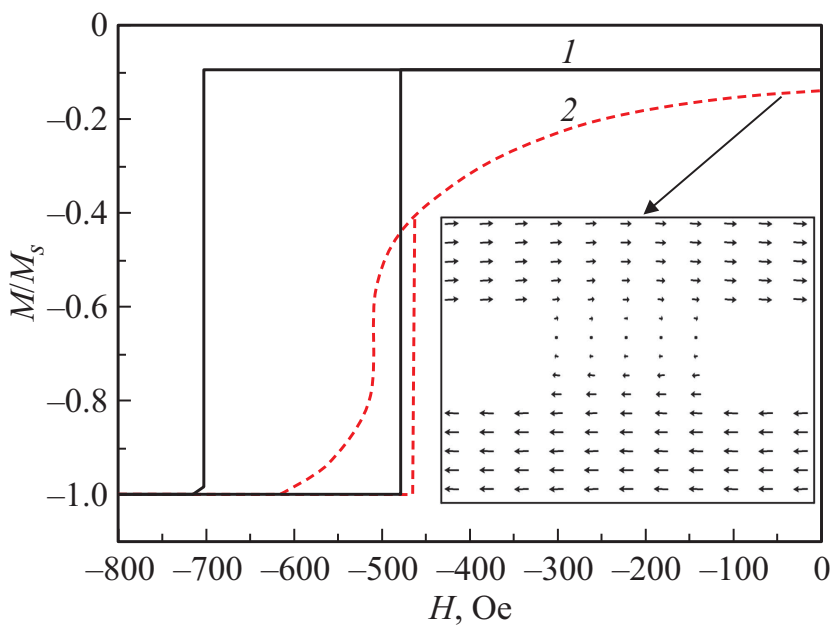

Рис. 4. Кривые намагничивания свободного ферромагнитного диска: 1 - без перемычки (сплошная черная линия); 2 с перемычкой диаметром $20 \mathrm{~nm}$ и высотой $10 \mathrm{~nm}$ (штриховая красная линия). На вставке: распределение намагниченности в системе ферромагнитных дисков, соответствующее указанному участку кривой.

го соотношения площадей сечения берегов и перемычки $S_{0} / S_{1}$, поэтому основная часть разворота магнитных моментов происходит в области сужения. Используемая расчетная модель не накладывает ограничений на направления магнитных моментов, в результате чего при уменьшении длины перемычки доменная стенка заходит в берега. Распределение намагниченности в исследуемой системе представлено на рис. 3. Подобная ситуация была рассмотрена в работе [8] для пленочных наномостиков, в которых доменная стенка в зависимости от величины константы анизотропии и геометрических параметров планарной системы заходила в один из берегов.

На практике особый интерес представляет сдвиг кривой намагничивания свободного слоя при добавлении в систему магнитного филамента, соединяющего его с закрепленным слоем. Нами были смоделированы кривые намагничивания системы ферромагнитных дисков диаметром $100 \mathrm{~nm}$ и толщиной $10 \mathrm{~nm}$, один из которых был запиннингован на подслое с фиксированным направлением магнитных моментов, обеспечивающем магнитную жесткость закрепленного слоя. Наличие цилиндрической магнитной перемычки диаметром $20 \mathrm{~nm}$ и высотой $10 \mathrm{~nm}$ с осью, проходящей через центр дисков, приводит к смещению кривой намагничивания свободного слоя и изменению ее формы, что обусловлено появлением обменного взаимодействия и возникновением доменной стенки (рис. 4). Сдвиг петель как для системы с филаментом, так и без него относительно нулевого магнитного поля связан с наличием магнитостатического взаимодействия с закрепленным диском.

Процесс перемагничивания происходил следующим образом. Изначально система была приведена в состояние насыщения во внешнем поле величиной 800 Ое.
При уменьшении величины поля до 460 Ое происходит резкое перемагничивание свободного слоя с образованием доменной стенки, локализованной в области перемычки. При этом намагниченность верхнего диска разворачивается не полностью из-за наличия обменного взаимодействия, стремящегося удержать магнитные моменты дисков сонаправленными. При дальнейшем уменьшении поля свободный слой продолжает плавно поворачиваться, уменьшая энергию магнитостатического взаимодействия. Обратный ход кривой намагничивания имеет плавный вид, обусловленный наличием доменной стенки.

\section{4. Заключение}

Таким образом, в работе методом микромагнитного моделирования исследована зависимость структуры и энергии доменной стенки, локализованной в области перемычки, связывающей ферромагнитные пленки, от геометрических параметров системы. Продемонстрирован эффект изменения формы и положения кривой намагничивания свободного слоя системы ферромагнитных дисков, обусловленный наличием обменного взаимодействия через магнитный филамент.

\section{Финансирование работы}

Работа выполнена при поддержке Российского научного фонда (проект 16-12-10340).

\section{Конфликт интересов}

Авторы заявляют, что у них нет конфликта интересов.

\section{Список литературы}

[1] H. Jang, O.A. Kirillov, O.D. Jurchescu, C.A. Richter. Appl. Phys. Lett. 100, 43510 (2012).

[2] T. Sakamoto, K. Lister, N. Banno, T. Hasegawa, K. Terabe, M. Aono. Appl. Phys. Lett. 91, 092110 (2007).

[3] J. Sun, Q. Liu, H. Xie, X. Wu, F. Xu, T. Xu, S. Long, H. Lv, Y. Li, L. Sun, M. Liu. Appl. Phys. Lett. 102, 053502 (2013).

[4] Z. Yang, Q. Zhan(a), X. Zhu, Y. Liu, H. Yang, B. Hu, J. Shang, L. Pan, B. Chen, R. Li. EPL 108, 58004 (2014).

[5] V.M. Uzdin, A. Vega. Nanotechnology 19, 315401 (2008).

[6] M.J. Donahue, D.G. Porter. Interagency Report NISTIR 6376. National Institute of Standards and Technology, Gaithersburg; http://math.nist.gov/oommf/.

[7] P. Bruno. Phys. Rev. Lett. 83, 2425 (1999).

[8] К.А. Звездин, А.В. Хвальковский. ФТТ 47, 1137 (2005).

Редактор Д.В. Жуманов 